\title{
Event-Related Periodic Interval of Time Data Type
}

National Cancer Institute

\section{Source}

National Cancer Institute. Event-Related Periodic Interval of Time Data Type. NCI

Thesaurus. Code $C 95658$.

A data type comprised of an interval of time over which an event or activity occurs. 